\title{
Sodium-Ion Intercalation Mechanism in MXene Nanosheets
}

\author{
Satoshi Kajiyama, ${ }^{\dagger}$ Lucie Szabova,${ }^{+}$Keitaro Sodeyama, ${ }^{\ddagger}{ }^{\star \|}$ Hiroki Iinuma, ${ }^{\dagger}$ Ryohei Morita,${ }^{\S}$ \\ Kazuma Gotoh, ${ }^{\mathcal{S}, \|}$ Yoshitaka Tateyama, ${ }^{*, \|}$ Masashi Okubo, ${ }^{\dot{*} \|}$ and Atsuo Yamada ${ }^{*}, \dot{*}, \|$
}

$\dagger$ Department of Chemical System Engineering, The University of Tokyo, 7-3-1 Hongo, Bunkyo-ku, Tokyo 113-8656, Japan

$\$$ International Center for Materials Nanoarchitectonics, National Institute for Materials Science, 1-1 Namiki, Tsukuba, Ibaraki 305-0044, Japan §Graduate School of Natural Science and Technology, Okayama University, 3-1-1 Tsushima-naka, Okayama 700-8530, Japan |Elements Strategy Initiative for Catalysts \& Batteries (ESICB), Kyoto University, Nishikyo-ku, Kyoto 615-8510, Japan

*To whom correspondence should be addressed: yamada@chemsys.t.u-tokyo.ac.jp 
Table S1. Elemental analysis for $\mathrm{Ti}_{3} \mathrm{AlC}_{2}$ and $\mathrm{MXene} \mathrm{Ti}_{3} \mathrm{C}_{2} \mathrm{~T}_{x}$ with EDX spectroscopy.

\begin{tabular}{cccccc}
\hline & $\mathrm{Ti}(\%)$ & $\mathrm{C}(\%)$ & $\mathrm{Al}(\%)$ & $\mathrm{O}(\%)$ & $\mathrm{F} \mathrm{( \% )}$ \\
\hline As synthesized $\mathrm{Ti}_{3} \mathrm{AlC}_{2}$ & 53.75 & 31.70 & 14.55 & - & - \\
$\mathrm{Ti}_{3} \mathrm{C}_{2} \mathrm{~T}_{x}$ after HF treatment & 57.37 & 31.88 & 0.37 & 4.26 & 6.13 \\
\hline
\end{tabular}

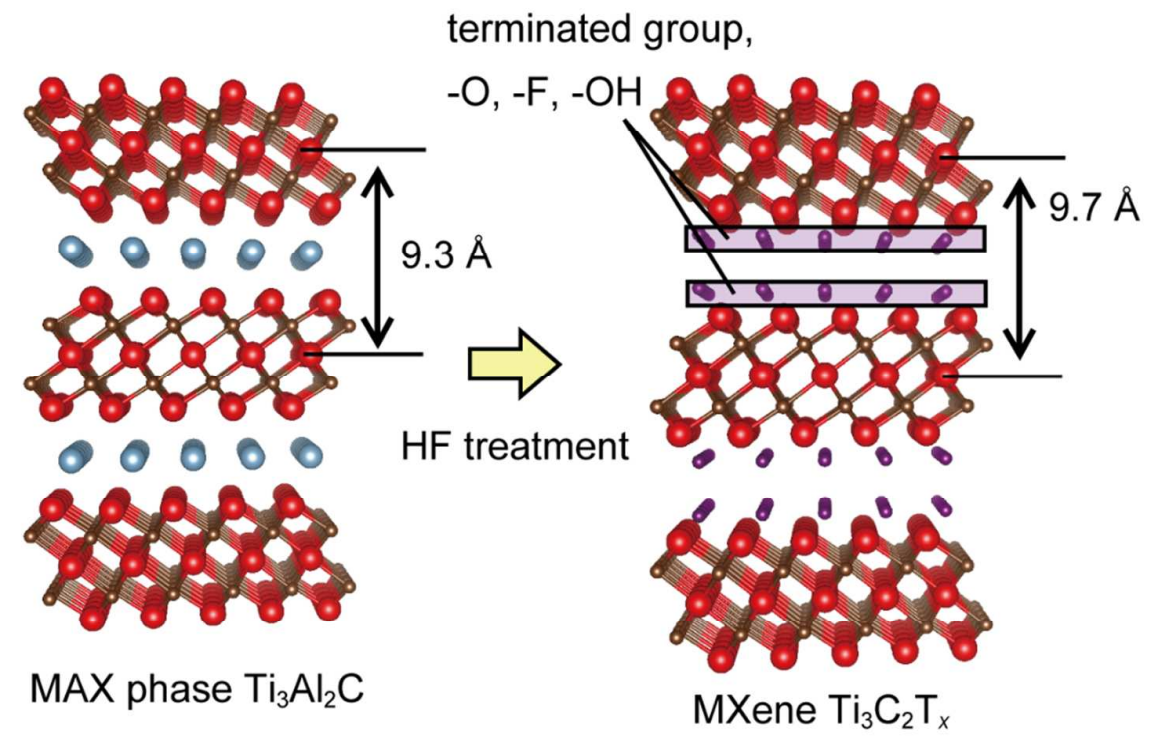

Scheme S1. Schematic illustration for formation of MXene $\mathrm{Ti}_{3} \mathrm{C}_{2} \mathrm{~T}_{x}$ by HF treatment. 


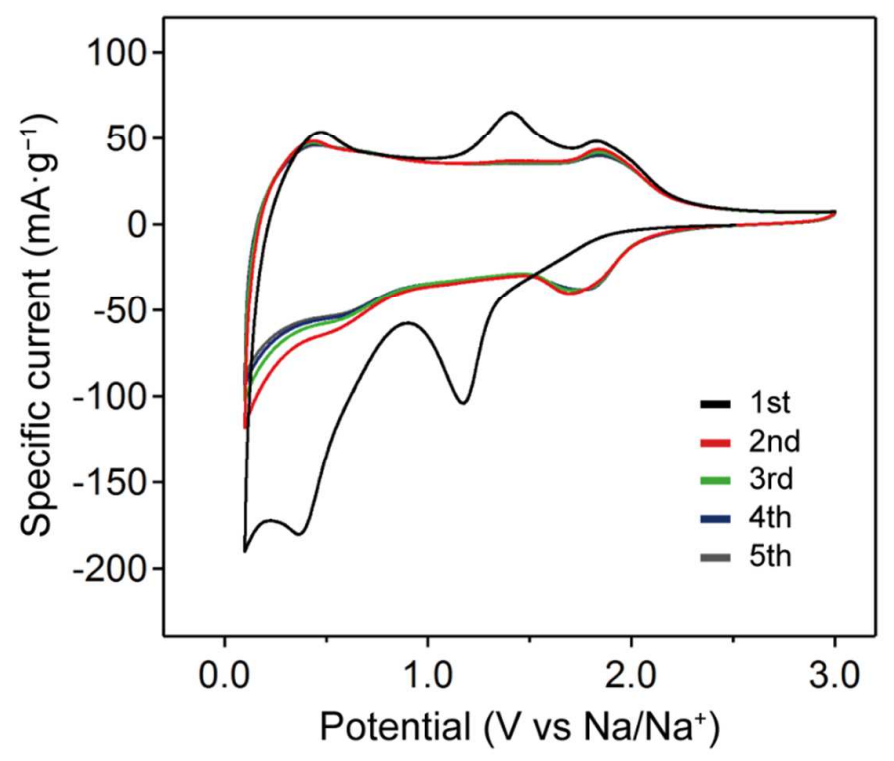

Figure S1. Cyclic voltammetry curves for $\mathrm{Ti}_{3} \mathrm{C}_{2} \mathrm{~T}_{\mathrm{x}}$ for the initial 5 cycles with the sweep rate of $0.2 \mathrm{mV} / \mathrm{s}$.

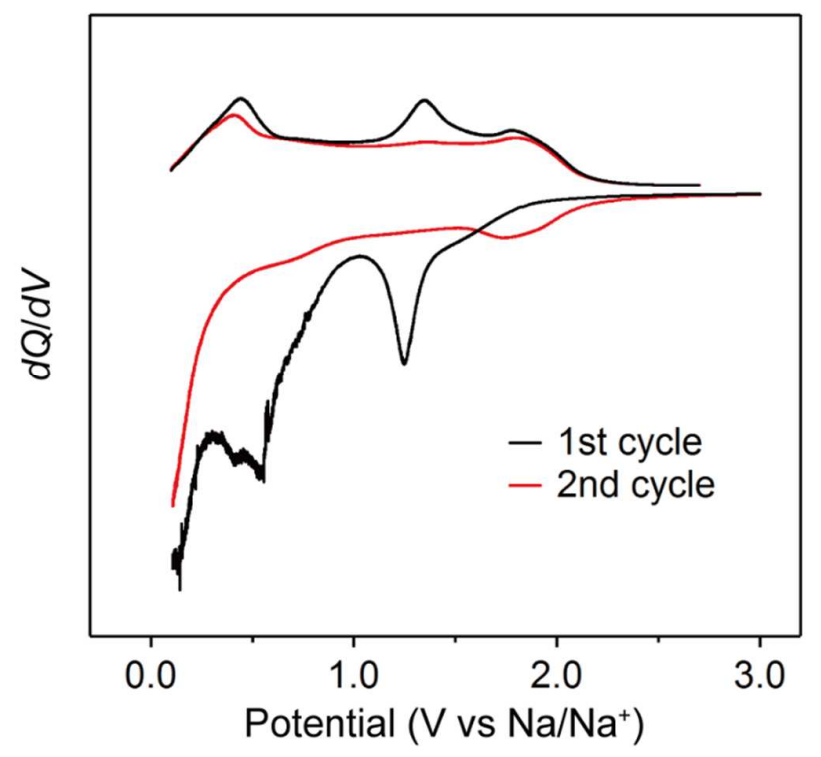

Figure S2. $d Q / d V$ plot for $\mathrm{Ti}_{3} \mathrm{C}_{2} \mathrm{~T}_{\mathrm{x}}$ with the constant current of $20 \mathrm{~mA} / \mathrm{g}$ for the initial two cycles. 


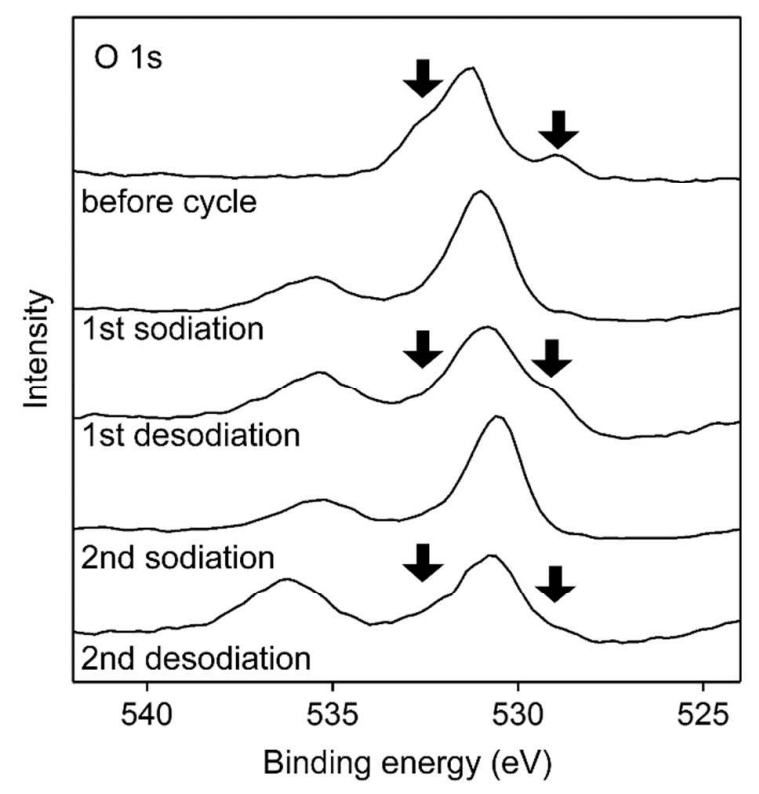

Figure S3. Ex situ XPS spectra for oxygen $1 \mathrm{~s}$ in $\mathrm{Ti}_{3} \mathrm{C}_{2} \mathrm{~T}_{x}$ during the initial two cycles.

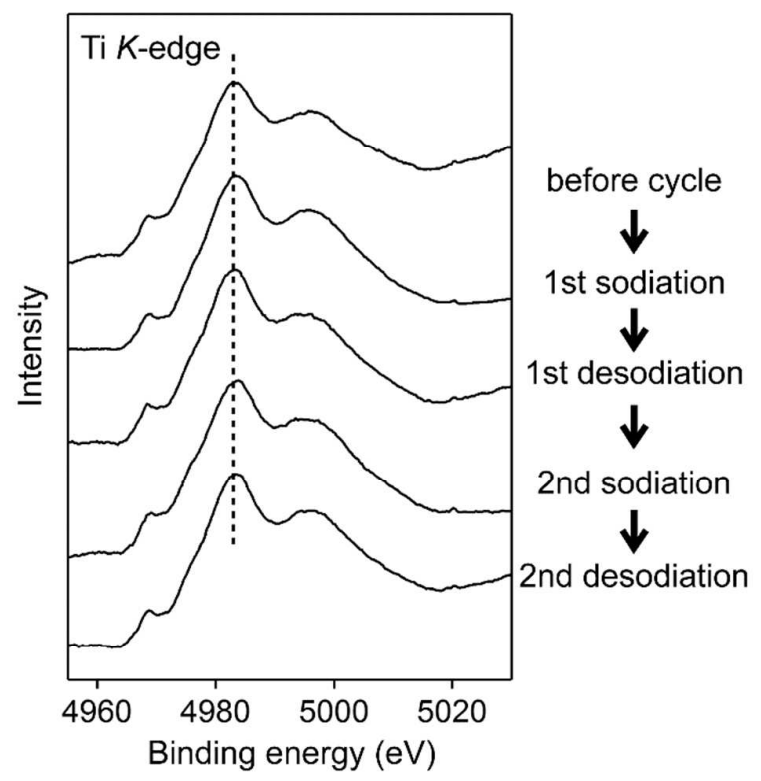

Figure S4. Ex situ XANES spectra for Ti $K$-edge of $\mathrm{Ti}_{3} \mathrm{C}_{2} \mathrm{~T}_{x}$ during the initial two cycles. 


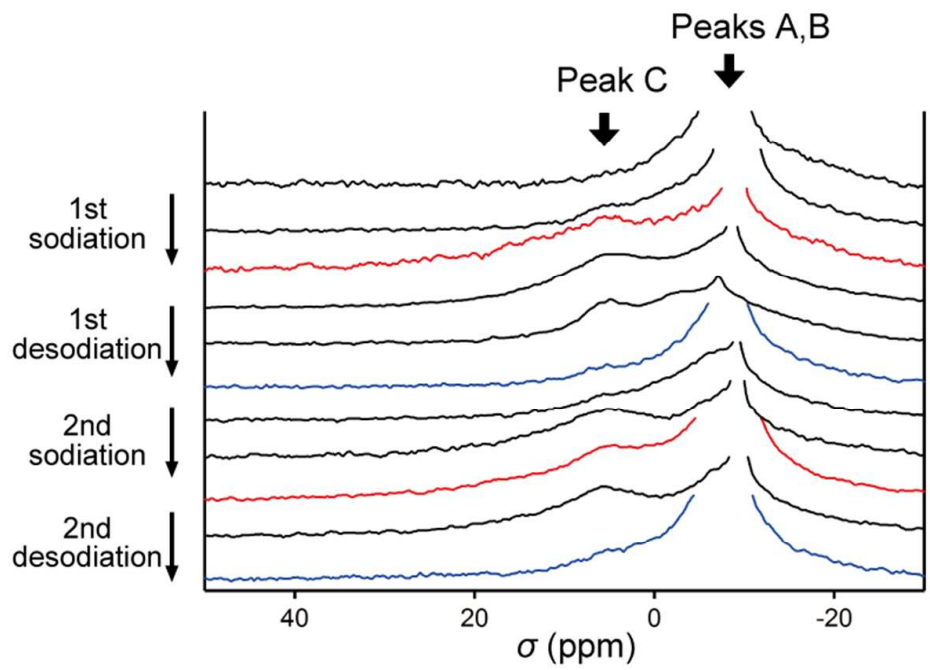

Figure S5. NMR signals during the initial two cycles. The signal intensity is normalized by the area of peak B. The red and blue lines correspond to the fully-sodiated $(0.1 \mathrm{~V})$ and fully-desodiated (3.0 V) states, respectively. 

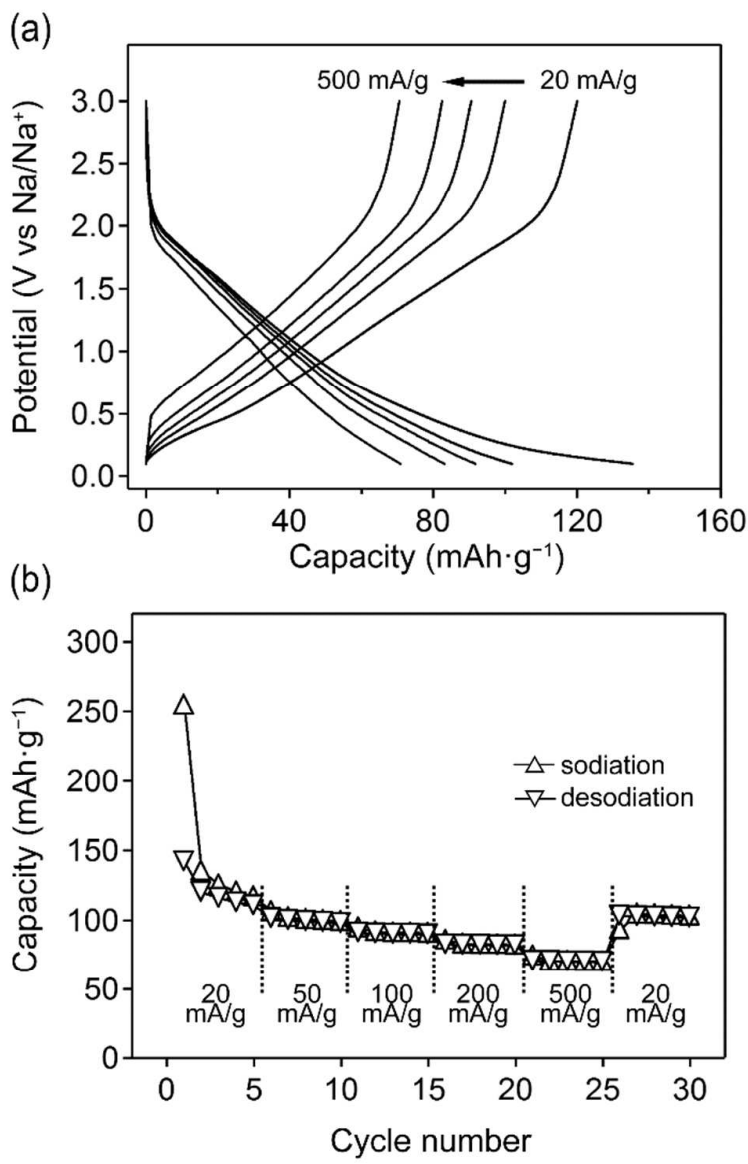

Figure S6. Rate properties for $\mathrm{MXene} \mathrm{Ti}_{3} \mathrm{C}_{2} \mathrm{~T}_{x}$ in $1 \mathrm{M} \mathrm{NaPF}$ /ethylene carbonate-diethyl carbonate (EC-DEC, 1:1 v/v\%) electrolyte. 